Thorax (1975), 30, 535.

\title{
Coronary artery fistula: report of three cases
}

\author{
DAVID WHEATLEY, ERIC N. COLEMAN, \\ and JOHN M. REID \\ Department of Cardiology and University Department of Child Health, Royal Hospital for \\ Sick Children, Glasgow, and the Cardio-Thoracic Unit, Mearnskirk Hospital
}

\begin{abstract}
Wheatley, D., Coleman, E. N., and Reid, J. M. (1975). Thorax, 30, 535-538. Coronary artery fistula: report of three cases. Three children are described with a right coronary artery fistula communicating with a right heart chamber. Each had a continuous murmur like that of a patent ductus arteriosus but situated at a lower level. Aortography established the diagnosis and excluded any accompanying malformation. It is concluded that to prevent complications surgical treatment should be recommended.
\end{abstract}

Communications between a coronary artery and a chamber of the heart are uncommon (McNamara and Gross, 1969) and from the evidence of the literature on the subject they would appear to be particularly so in the United Kingdom. This paper reports three recent cases.

\section{CASE HISTORIES}

CASE 1 A heart murmur was first heard in this girl at the age of 1 month. Her progress had been uneventful, but she was referred to the cardiac clinic of the Royal Hospital for Sick Children, Glasgow, when aged 18 months because of a loud continuous murmur at the left sternal border, maximal in the fourth left intercostal space. The chest radiograph disclosed slight prominence of the left ventricle, and the electrocardiogram mild left ventricular hypertrophy. She remained symptom-free. Investigation was recommended at the age of $4 \frac{1}{2}$ years. The pulses were collapsing, and blood pressure measured $95 / 40 \mathrm{mmHg}$. Cardiac catheterization indicated normal pressures in the right atrium, right ventricle, and main pulmonary artery, but there was a rise in oxygen saturation in the right ventricle, with a $Q p: Q s=1 \cdot 4: 1$. An aortic root angiogram demonstrated a fistulous communication from a dilated tortuous right coronary artery to the right ventricle.

A right anterolateral thoracotomy was performed at the age of 5 years. The right coronary artery was grossly dilated from its origin to a point just distal to the marginal branch. The coronary artery then penetrated the right ventricular muscle. The vessel was ligated at the point of its disappearance, no electrocardiographic changes having occurred after 15 minutes' preliminary clamping. On return from the operating theatre marked depression followed by elevation of the S-T segment in standard leads II and III was noted but these changes resolved within two days. Recovery was smooth. When seen for outpatient review six months later she was well and there was no murmur.

CASE 2 An asymptomatic male infant was referred at the age of 6 weeks following the discovery of a heart murmur. The initial diagnosis was considered to be ventricular septal defect with aortic regurgitation. Investigation was deferred as he remained well. Outpatient supervision continued until, at the age of 9 years, he was admitted for cardiac catheterization. A loud continuous murmur was audible at the left lower sternal border, the pulses were collapsing, and the blood pressure was $120 / 65 \mathrm{mmHg}$. The chest radiograph and electrocardiogram had remained within normal limits. Right heart catheter studies confirmed the presence of a left-to-right shunt apparently at ventricular level, with a $Q p: Q s=1 \cdot 25: 1$. Mild pulmonary hypertension was present, the pressure in the main pulmonary artery being $43 / 26 \mathrm{mmHg}$. Selective angiocardiography revealed no ventricular septal defect nor aortic valve disease but a grossly dilated, tortuous right coronary artery which entered the right atrium via the coronary sinus (Figure).

A vertical sternotomy was used. The right coronary artery was readily visible as a dilated, tortuous vessel with apparently normal right ventricular branches. The dilated vessel ran in the 


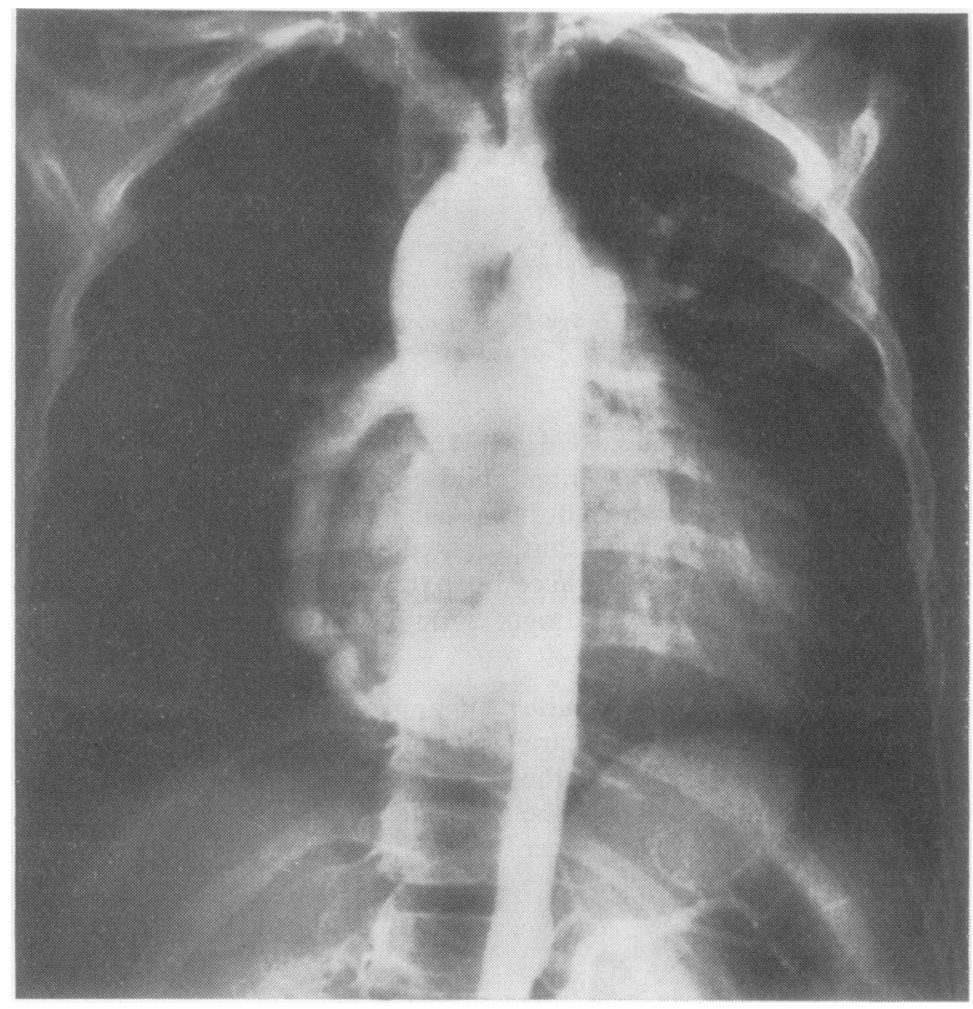

FIGURE Case 2. Aortic root angiogram showing dilated, tortuous right coronary artery with fistula draining into right ventricle.

atrioventricular groove to the diaphragmatic surface of the heart and terminated in a fistulous communication with a dilated coronary sinus. The posterior descending coronary artery was shown to be a continuation of the left circumflex branch. During a brief period of cardiopulmonary bypass, to allow the heart to be retracted, the termination of the right coronary artery was ligated. No electrocardiographic changes occurred, and discontinuation of cardiopulmonary bypass was uneventful. Recovery was smooth with no complications. The electrocardiogram at the time of the patient's discharge from hospital showed depression of the S-T segments in the precordial leads V1-V4. These changes had resolved when the patient was seen six months later, at which time he was healthy.

CASE 3 A male infant was found to have a cardiac murmur on routine examination at the age of 4 weeks. There were no signs of cardiac failure and outpatient supervision was continued until the age of 5 years. He was then admitted for further investigation. Examination revealed a rather pale, $\underset{x}{\stackrel{0}{叉}}$ undersized child with collapsing pulses. The blood pressure measured $90 / 40 \mathrm{mmHg}$. A continuous murmur was audible at the pulmonary area, maxi- 8 mal at the third interspace at the left sternal border. There was no radiographic evidence of $ᄋ$ cardiac enlargement and the electrocardiogram was normal. The fact that the murmur was maximal below the pulmonary area cast doubt on the diagnosis of patent ductus arteriosus. Cardiac $O r$ catheterization confirmed the presence of a left- $N$ to-right shunt at ventricular level with a Qp : Qs $=1 \cdot 25: 1$. The pressure in the main pulmonary 0 artery was normal $(22 / 10 \mathrm{mmHg})$. Left heart catheterization showed neither aortic valve disease $\overparen{\odot}$

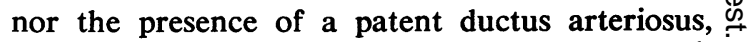
and selective angiocardiography in the left ventri- $\square$ cle and at the aortic root demonstrated a dilated, tortuous right coronary artery with a fistula ap- $\bigcirc$ parently to the anterior wall of the right ventricle; $\mathbb{Q}$ the left coronary artery was normal.

A vertical sternotomy was used. The origin of the right coronary artery was of normal size but a 
saccular aneurysmal dilatation was present between 2 and $5 \mathrm{~cm}$ from the origin. There were normal branches both proximal and distal to this dilated segment. Cardiopulmonary bypass allowed careful dissection of the right coronary artery, and the aneurysmal area was completely mobilized. The artery beyond this point was displayed with its branches but no fistula could be found. Ventriculotomy to pursue the search for a small fistula did not seem justified. A thrill was palpable at the aneurysmal area, and the epicardium was plicated over the aneurysm to reinforce the vessel in this region. Bypass was discontinued without difficulty and convalescence was uneventful. At subsequent outpatient attendance the continuous murmur was still present, presumably due to a small fistula which at operation had escaped detection. Further surgery is not contemplated as the shunt seems small.

\section{DISCUSSION}

Although coronary artery fistulae may involve either main vessel, the right is the more commonly implicated (Azcuna et al., 1971). The fistula terminates most frequently in a chamber or vessel of the right heart, the order of frequency being right ventricle, right atrium (including coronary sinus), pulmonary artery, and superior vena cava. Drainage into the left ventricle is exceptional (Nadas, 1963; McNamara and Gross, 1969; Okuda, Tsuneda, and Morishima, 1973). Although most occur singly, multiple fistulae are described (McNamara and Gross, 1969). Sabbagh et al. (1973) considered that coronary artery fistula is in most instances an isolated anomaly, and other authors, notably Ogden and Stansel (1972) and McNamara and Gross (1969), have estimated that additional cardiac abnormalities are present in only $20 \%$ of patients.

The clinical findings have been well documented (Azcuna et al., 1971; de Nef, Varghese, and Losekoot, 1971). In children it is exceptional for any symptoms to be present, although these may arise in later life in untreated cases when the shunt volume is large. Cardiomegaly may be present. The most frequent abnormal clinical sign (and for diagnosis the most useful) is a continuous murmur closely simulating that of a patent ductus arteriosus, except that it is best heard in the third or fourth interspace at the left sternal border rather than at the pulmonary area. Inappropriate surgery for a mistaken diagnosis of patent ductus arteriosus has occurred in the absence of full investigation (Edis et al., 1971). Other conditions which require differentiation are aortopulmonary fenestration, persistent truncus arteriosus, ruptured aortic sinus aneurysm, and ventricular septal defect with aortic regurgitation (Nadas, 1963). This last condition was the provisional diagnosis in one of our patients before investigation.

Most authors have indicated that complications can arise in untreated cases. Koops et al. (1973) reported pulmonary hypertension, congestive cardiac failure, infective endocarditis, rupture or thrombosis of the fistula, and myocardial ischaemia distal to the fistula. They therefore unequivocally advocated the prophylactic ligation of all fistulae and reported ten successfully treated cases. Effler et al. (1967) and McNamara and Gross (1969) also advised surgical closure as being effective and relatively safe. Jaffe et al. (1973), however, followed six patients from three and a half to 17 years without operation and demonstrated symptomatic, electrocardiographic, haemodynamic, and angiographic stability. They concluded that when the shunt was either small or moderate no deterioration occurred over a long period and, furthermore, that operative closure does not necessarily reduce the size of the dilated proximal coronary artery. Björk and Björk (1965) also questioned the advisability of surgery in every patient and restricted it to those with a large shunt.

McNamara and Gross (1969) summarized current surgical management as consisting of interruption of the fistulous communication, leaving the feeding coronary artery intact to continue to supply the myocardium in its territory. The earlier methods of proximal coronary artery ligation or of ligation immediately proximal and immediately distal to the fistula have been superseded because of the incidence of dysrhythmia and myocardial ischaemia. The surgical approach is dictated by the anatomical site of the fistula, as defined by angiography, and may be from right or left thoracotomy or vertical sternotomy. It is recommended that facilities for cardiopulmonary bypass be at hand in all cases. It is possible to identify and ligate the communication without cardiopulmonary bypass in some cases (as in our case 1) but in others the communication may be accessible only after displacement of the heart, necessitating cardiopulmonary bypass. This gives further security in the event of unexpected difficulties of dissection or bleeding. Such a situation arose in our third patient in whom bypass was necessary to allow careful dissection. In spite of this the fistula escaped detection, presumably being mistaken for a normal coronary branch near the site of the aneurysm. 
McNamara and Gross (1969) had no deaths in their series of six patients treated surgically and their review of the literature yielded 93 patients so treated with only three deaths. Surgery is, therefore, safe, and would appear to prevent symptoms and complications in later life. We have little difficulty in recommending operation in all cases because even small shunts carry the risk of infective endocarditis and because insufficient longterm studies of the natural history have been reported, especially those which would follow patients to an age at which the effects of advancing atherosclerosis on the haemodynamics of an abnormal coronary vasculature may be profound.

We are indebted to our surgical colleagues, Messrs. R. S. Barclay, T. M. Welsh, and N. McSwan, and to Drs. E. Sweet and M. McNair for radiological assistance.

\section{REFERENCES}

Azcuna, J. I., Cabrera, A., Arruza, F., and Iriarte, M. (1971). Fistulae between the coronary arteries and the right cavities of the heart. Report of three cases treated surgically. British Heart Journal, 33, 451.

Björk, V. O. and Björk, L. (1965). Coronary artery fistula. Journal of Thoracic and Cardiovascular Surgery, 49, 921.

Edis, A. J., Schattenberg, T. T., Feldt, R. H., and Danielson, G. K. (1971). Congenital coronary artery fistula: surgical considerations and results of operation. Circulation, 44, p. 161. Suppl. II.

Effler, D. B., Sheldon, W. C., Turner, J. J., and Groves, L. K. (1967). Coronary arteriovenous fistulas: Diagnosis and surgical management. Report of fifteen cases. Surgery, 61, 1, 41 .

Jaffe, R. B., Glancy, D. L., Epstein, S. E., Brown, $\frac{\bar{\sigma}}{\square}$ B. G., and Morrow, A. G. (1973). Coronary $\mathbb{Q}$ arterial-right heart fistulae. Long-term observations in seven patients. Circulation, 47, 133.

Koops, B., Kerber, R. E., Wexler, L., and Greene, $\vec{O}$ R. A. (1973). Congenital coronary artery anomalies. Journal of American Medical Associa- $\vec{\omega}$ tion, 226, 1425 .

Nadas, A. (1963). Pediatric Cardiology, 2nd edition, $\overrightarrow{\vec{x}}$ p. 515. W. B. Saunders Company, Philadelphiaw and London.

de Nef, J. J. E., Varghese, P. J., and Losekoot, G.'̈ (1971). Congenital coronary artery fistula. Analysis of 17 cases. British Heart Journal, 33, 857.

McNamara, J. J. and Gross, R. E. (1969). Congenital coronary artery fistula. Surgery, 65, 1, 59.

Ogden, J. A. and Stansel, H. C. (1972). Coronaryô arterial fistulas terminating in the coronaryo venous system. Journal of Thoracic and Cardiovascular Surgery, 63, 172.

Okuda, Y., Tsuneda, T., and Morishima, A. (1973). जे Right coronary artery to left ventricle fistula. The sixth case in the literature and discussion. Japanese Heart Journal, 14, 184.

Sabbagh, A. H., Schocket, L. I., Griffin, T., Anderson R. M., Goldberg, S., Fritz, J. M., and O'Hare, J\% (1973). Congenital coronary artery fistula $\mathbb{\mathscr { Q }}$ Journal of Thoracic and Cardiovascular Surgery $\overrightarrow{\vec{F}}$ 66, 794.

Requests for reprints to: Dr. John Reid, Department of Cardiology, Royal Hospital for Sick Children? Glasgow. 